\title{
HISTÓRIAS DE APRENDIZ: MEMÓRIAS, NARRATIVAS E FORMAÇÃO DOCENTE
}

\author{
Lúcia Gracia FERREIRA ${ }^{1}$
}

RESUMO: Este estudo tem como objetivo relatar histórias de aprendiz produzidas no âmbito do curso de extensão "Formação de professores: um desafio da contemporaneidade", desenvolvido na Universidade Estadual do Sudoeste da Bahia, Campus de Itapetinga, e os aspectos formativos presentes nas histórias. A discussão do curso incidia sobre a formação de professores na contemporaneidade e os encontros eram realizados semanalmente. Assim, este trabalho buscou identificar nas histórias de aprendiz narradas, memórias e nessas as experiências formativas nela presente. Para alguns eram apenas histórias, para outros lembranças, aqui mostro que é mais que isso, é formação. A partir da análise das narrativas foi possível perceber como sujeitos mudaram, formaram, viveram. Assim, considero as histórias de aprendiz, narrativas de fragmentos da vida, que possibilita reflexão, que possibilita a autoformação.

PALAVRAS-CHAVE: Escritas de si. Aprendizagens. Autoformação.

\section{INTRODUÇÃO}

A discussão sobre memória, narrativas e formação tem sido de meu interesse desde 2008 quando ingressei no Programa de Pós-Graduação em Educação e Contemporaneidade, na Universidade do Estado da Bahia/Salvador, pois passei a estudar, desde então, as histórias de vida de professores rurais, cujo corpus da pesquisa foi composto por narrativas de formação, possíveis através da memória. Foi nesse programa que ouvir falar pela primeira vez em história de aprendiz, na disciplina Formação do Educador. Não fiz a minha história de aprendiz, mas ouvi muitas delas e aprendi, ouvindo, um pouco mais sobre a formação.

Dessa forma, a partir da realização do Projeto de extensão "Formação de professores: um desafio da contemporaneidade", na Universidade Estadual do Sudoeste da Bahia, Campus de Itapetinga, em forma de curso, que acontecia nas quartas-feiras, no turno vespertino, foi possível realizar a atividade das "histórias de aprendiz", que

\footnotetext{
${ }^{1}$ Professor Adjunto. UFRB - Universidade Federal do Recôncavo da Bahia. Doutora em Educação. UFSCar - Universidade Federal de São Carlos. Especialista em Linguagem, Pesquisa e Ensino e graduação em Licenciatura em Pedagogia. UESB - Universidade Estadual do Sudoeste da Bahia. Itapetininga - BA - Brasil. 45700-000 - luciagferreira@ hotmail.com.
} 
eram quando iniciávamos o encontro. Foi uma atividade proveitosa, que se configurava numa escrita de duas a três laudas sobre um aspecto da vida, era uma história rápida, contada em poucos minutos, escrita em poucas páginas, mas com significado inestimável para quem escrevia. Percebi que estas histórias contribuíam para a formação desses cursistas, por isso resolvi contá-las.

\section{Formação de professores: o curso de extensão}

O momento histórico pelo qual passa a educação tem levado muitas pessoas a refletir nas mudanças nela provocada. Essas mudanças têm repercutido, principalmente, na profissão docente. Um processo educativo voltado para a transformação deve ser pensado por todos da sociedade, o que possibilita que todos pensem na educação como uma forma de adquirir conhecimento, contribuindo, assim, para a vida social. Contudo para que isso aconteça é extremamente necessário considerar o professor como mediador desse conhecimento. Sendo assim, a preparação desses profissionais é uma forma de aproximar as utopias da realidade.

No século atual continuamos a defrontar-nos com profundas transformações no campo da política, da economia e também da educação, que tem levantado discussões e feito surgir várias pesquisas sobre esses assuntos. Novos paradigmas têm surgido e, juntamente, as críticas. Isso tem feito aguçar uma discussão no âmbito da educação, principalmente no campo da formação de professores, que tem avançado e sido crescente. Nessa mesma perspectiva, esse trabalho vem trazer contribuições para se pensar a formação de professores a partir das exigências da contemporaneidade.

Nunes (2000), ao historicizar as políticas públicas de formação de professores, conclui que essa permeia entre avanços legais e recuos pragmáticos. Ao longo dessas trajetórias buscou-se melhorias na formação docente, mas o que vimos surgir foram formações diversificadas. O investimento na formação docente deve ser feito buscando efeitos que levem a transformação social. É claro, que a educação não vai sozinha transformar o mundo, mas ela é elemento fundamental para que essa transformação aconteça.

Acompanha-se através da trajetória das políticas públicas da formação docente que há uma definição do perfil do profissional docente e também uma reavaliação da preparação desses profissionais mediante de exigências legais. Ainda, percebe-se que há uma distância muito grande entre o real e o ideal que precisa ser minimizada. Partindo 
do ponto de vista que é nos professores que estão as esperanças de mudanças sociais e culturais, deve haver uma valorização bem maior desses profissionais, o que torna a sua formação um desafio do futuro que deve ser construído gradativamente. Profissionais comprometidos com a Educação e formados para atuar na área prática são o que queremos construir para atender a demanda educacional.

Perrenoud et al. (2002, p.15) diz que "[...] a qualidade de uma formação depende, sobretudo, de sua concepção”, ou seja, do que se pretende produzir. Assim, é a partir da educação que há uma busca de um conhecimento, capaz de possibilitar ações conjuntas e trabalho que levem ao êxtase humano de realização.

Para Tardif (2002, p.16), “[...] um primeiro fio condutor é que o saber dos professores deve ser compreendido em íntima relação com o trabalho deles na escola e na sala de aula”, com a função de levar esse conhecimento até a sociedade. Por isso é que a formação para o magistério deve levar em conta os saberes dos professores e as realidades específicas de seu trabalho cotidiano, valorizando-o e reconhecendo-o como essencial para a formação do homem. Então, preparar os professores é possibilitar a preparação também do homem.

Visto que a educação tem passado por mudanças e que não podemos ficar fora dela, é que proporcionaremos esse projeto de extensão que será desenvolvido em forma de curso. Os temas inseridos no curso foram voltados para a formação docente. Nessa perspectiva, este curso buscou fazer aflorar/reconhecer no participante o desejo de ensinar - força motriz da ação pedagógica. O curso foi, então, planejado no sentido de oferecer aos participantes a oportunidade de desenvolverem estudo e reflexão sobre os condicionantes didáticos, sociais e políticos, assim como éticos e estéticos que configuram a formação docente e, por conseguinte, a organização da sua prática.

Esse curso não teve a pretensão, tão somente de transferir conhecimentos, mas de possibilitar a desconstrução/construção e reconstrução constante de saberes e competências necessários ao trabalho educativo. Assim, a partir das reflexões conjuntas, os aspectos conceituais e pressupostos teóricos abordados deverão constituir-se em fundamentação básica concernente ao objetivo do curso e a possibilidade de inserção consciente dos participantes/educadores no contexto educacional.

O oferecimento desse curso foi despertado, primeiramente, por estar nesse momento, envolvida com a temática e tê-la definida como linha de pesquisa. Também porque lecionei na UESB/Itapetinga nos semestres 2011.2, 2012.1 e 2012.2 as disciplinas "Metodologia da Pesquisa Educacional", "Prática da Pesquisa Educacional" 
e "Elaboração de Trabalho Monográfico" no curso de Pedagogia e percebi que o tema "formação de professores" era raramente escolhido como tema de pesquisa, tornando-se pouco discutido entre os alunos. Dessa forma, o curso foi também uma tentativa de despertar nos alunos o interesse de pesquisar essa temática.

Outro ponto a ser destacado é o fato da UESB/Itapetinga ter quatro cursos de licenciatura - Pedagogia (matutino e noturno), Ciências Biológicas, Física e Química -, todos com funcionamento no noturno e o debate sobre formação de professores ser pouco fluente entre eles. Assim, o curso buscou promover não somente o debate, mas também a aproximação entre os alunos das diferentes licenciaturas e de diferentes profissionais da educação. Essa interação é importante para promover o debate.

O curso ainda buscou promover o aprofundamento de algumas questões que, muitas vezes, não são contempladas nas disciplinas contidas na estrutura curricular dos cursos de licenciatura. Portanto, academicamente, este buscou realizar discussões atualizadas sobre o professor e a/na contemporaneidade. Ainda abrangeu a certificação legal, por meio de um trabalho de formação continuada de professores, importante para a atualização dos conhecimentos e aquisição de saberes. Assim, teve como objetivo geral propor discussões sobre a formação dos professores, fornecendo-lhes uma visão global e abrangente sobre o tema, permitindo ao professor uma maior vivência, desenvolvendo visão crítica e mais ampla sobre a formação docente para que, com isso evidenciar sua aplicabilidade no mundo contemporâneo.

Este estudo interessa à universidade por ser o espaço próprio para possibilitar uma formação capaz de construir conhecimento, além de ser sua a responsabilidade institucional, por meio da prática pedagógica dos seus professores, de democratizar o acesso à pesquisa e a extensão. Sem esta democratização, a formação do professor se limitará às intenções dos teóricos, os poucos discutidos, utilizados durante toda a graduação.

Procurei desenvolver o curso de forma expositiva, integrada e renovadora. $\mathrm{O}$ curso foi desenvolvido de forma interativa, numa perspectiva multidimensional e interdisciplinar, possibilitando aos participantes uma visão dos conceitos básicos em torno das questões abordadas, com base em atividades teórico-vivenciais. Utilizei técnicas pedagógicas, fazendo uso de exposições participativas; dinâmicas de grupo; análise, parecer e discussão dos textos teóricos e histórias de aprendiz.

Alguns temas fizeram parte da lista de conteúdos do curso e outros temas surgiram nos momentos das discussões. São eles: histórico da formação de professores 
no Brasil; o desejo de ensinar e o trabalho docente; políticas de formação de professores; prática e formação de professores; formação e identidade docente; a subjetividade na formação de professores; memórias e formação de professores; narrativas, (Auto)biografia e Histórias de vida de professores; pesquisa em formação de professores; saberes docentes; autonomia e cotidiano na formação docente; currículo e formação docente; professor pesquisador; magistério e gênero; o professor multirreferencial; tecnologia e formação de professores.

Diante dos complexos desafios que a globalização apresenta, a realidade educacional se encontra questionada e pressionada a mudar. Os sentidos e significados sobre a profissão docente e a sua formação, construídos pelos estudantes das licenciaturas são de fundamental importância para a sua prática profissional, já que guiam suas ações dentro e fora da escola. As representações desses futuros professores e professores, no contexto da formação profissional, são importantes também, para desvelar a concepção e atitude frente à prática educativa.

À universidade, interessa também, para tomar conhecimento do nível de democratização ou de distanciamento das práticas pesquisadoras. $\mathrm{Na}$ sociedade do conhecimento, há representações de professores construídas, transformadas e consolidadas pelas informações e imagens que as tecnologias comunicacionais difundem no cotidiano. É neste quadro que este trabalho se insere e torna-se importante para o fortalecimento da profissionalização e para a sistematização e transformação da prática e formação do professor.

Nessa perspectiva, as histórias de aprendiz fazem parte dessa formação. Essas foram produzidas no período do curso - agosto a dezembro do ano de 2012. Eram escritas pelos alunos e trazidas para a universidade onde eram realizadas as leituras. Havia também a escuta, através da qual a formação também foi possível.

\section{Histórias de aprendiz: quais são elas?}

Recebi 18 histórias de aprendiz, mas durante o curso foram lidas mais que isso. As histórias não seguiam um padrão, algumas continham uma, outras duas ou três laudas; algumas continham fotos; algumas foram lidas, outras, cantadas; em algumas leituras houve choro e em outras risos. Dessa forma, escolhi cinco para serem expostas aqui para, através delas, discutirmos memórias, narrativas e formação. 
As memórias envolve a dimensão do tempo passado que se relaciona ao presente e ao futuro. Segundo Izquierdo (2004 apud BRANDÃO, 2008, p.9) memória é:

\begin{abstract}
A aquisição, conservação e evocação das informações, dos fatos vividos por cada indivíduo, e que tanto a formação quanto a sua extinção - os esquecimentos - estão vinculados a um sistema complexo, sendo que a formação das memórias de longa duração " [...] dependem de forma direta das modificações bioquímicas estruturais, derivadas, por sua vez, da síntese de novas proteínas durante e depois da formação de cada uma delas".
\end{abstract}

Essa memória de longa duração é também chamada pelo autor de memória autobiográfica. Dela nos fazemos, pois ele diz que somos aquilo que lembramos e esquecemos. É dessa maneira que vamos formando quem somos, através de nossas memórias que constituem as identidades e historicidade dos indivíduos.

Assim, as narrativas, escritas e/ou orais, questionam os sentidos das experiências de vida, aprendizagens e saberes, e, através das memórias de si, permitem o entendimento da formação (SOUZA, 2006). Por isso, as nossas trajetórias de vida nos admitem afirmar que é possível aprender com as experiências. Essas narrativas permitem pensar sobre as experiências, aprendizagens e os sentidos presentes na formação, pois foram adquiridos num contexto individual e coletivo e fazem parte do processo identitário do indivíduo. Pois, “[...] aprendizagem experiencial e formação se integram porque estão alicerçadas numa prática, num saber-fazer pelas experiências”. (SOUZA, 2006, p.94).

As histórias de aprendiz revelam identidades dos sujeitos que narram e aspectos de sua formação. Conforme fala de Paloma, abaixo.

Demorei para começar escrever essas lembranças, embora tenha passado por muitos momentos marcantes no meu percurso de aprendiz, é difícil associar um que se destaque. Sempre fui uma ótima aluna, era elogiada pelos professores e também muito cobrada por eles. Sou de uma família de educadores, minha mãe, considerada uma excelente professora é completamente apaixonada pela educação. Assim, sempre estive rodeada por conversas e discussões acerca da educação, dos problemas vivenciados pelos professores, das dificuldade da escola, das políticas necessárias.

O fato de ser filha de professora, como tudo na vida, também tem dois lados. Ás vezes, acho que a cobrança marcou mais meu processo de aprendizagem. Hoje, sou extremamente ansiosa com resultados, pode não ser devido a isso, mas essa cobrança que filha de professora tinha que ser uma excelente aluna e tirar 10, contribuiu. Com certeza contribuiu. Assim, muito cobrada pelos 
professores e apresentando bons resultados passei pela educação básica e ensino médio.

Nunca quis ser professora, dizia que nunca iria cursar Pedagogia, pra quê? Para sofrer como minha mãe. Não, isso eu não queria. Sonhava em atuar na área de saúde. Porém, ao chegar na época do vestibular, passava por um momento delicado. Meu pai havia sofrido o $3^{o} A V C$, e encontrava-se bastante debilitado, precisava de cuidados. Minha mãe, professora da zona rural já havia solicitado licença e tinha que voltar logo para a escola. Eu portanto, teria que prestar vestibular para o campus de Itapetinga. Fiz a inscrição para Engenharia Ambiental, pois no site havia a informação que o curso era matutino. Após saber que era diurno, enfrentei um longo processo para conseguir cancelar a inscrição e poder fazer outra. No final, tudo certo. Nova oportunidade de escolher um curso. E adivinha o que meu restou? Sim, Pedagogia. Como minha irmã estudava à tarde, eu teria que estudar pela manhã para ficar com meu pai no turno vespertino. E o único curso apenas matutino era o de Pedagogia. Para uns, ironia do destino. Para mim, história escrita pelos dedos de Deus. Eu tinha que cursar pedagogia! Prova disso, passei em $1^{\circ}$ lugar.

Já, no curso, demorei para me reconhecer enquanto Pedagoga, nosso curso era meio apagado. Não havia nada que mobilizasse em mim um sentimento bom pelo curso. Até que no $3^{o}$ semestre essa história começou a mudar. Sempre gostei muito de política, das melhorias que poderiam ser feitas na educação. Acho que as conversas da minha mãe acabaram despertando isso em mim. Então, quando tive a oportunidade de participar do DA [Diretório Acadêmico] de Pedagogia, não perdi tempo. Após, a eleição, estávamos entusiasmadas, queríamos lutar por mudanças, queríamos mobilizar os professores que muitas vezes estavam apáticos aos nosso anseios. Por meio de uma carta, lida durante uma reunião do departamento, expressamos todas nossas angustias. Além disso, enviamos essas carta para diversos DA's, de outros estados também. Descobrimos que outros alunos de pedagogia passavam pelas mesmas necessidades e nos apoiavam. Mas descobrimos também, como discursos puramente sentimentais, podem "fazer" a cabeça das pessoas. E como alunos de "nivel superior" também podem ser facilmente manipulados. Fomos tachadas como "loucas" pelos colegas de curso e professores. Loucas, por querer melhorias, por querer livros na biblioteca e parar de cometer o crime da xerox, loucas por não aceitar professor alcoolizado dentro da sala de aula, loucas por querer que o ensino, pesquisa e extensão acontecessem, loucas por denunciar professores que simplesmente entravam na sala, passavam uma lista de presença e iam embora 10 minutos depois. ERAMOS REALMENTE LOUCAS, estávamos indo contra o sistema.

Ao mesmo tempo, fui convidada a participar de uma pesquisa sobre os 10 anos do curso de Pedagogia, realizada por uma ex-aluna: Lucia Gracia. Bem, eu estava completamente envolvida com o curso e isso seria bom para mim. Além disso, meu pai havia falecido e eu tinha que ocupar meu tempo para amenizar a terrivel dor que sentia. Durante a pesquisa, além de conhecer a fundo o passado e o presente do curso, as historias dos ex-alunos e perspectivas dos novos, tive a oportunidade de conhecer Lucia e acompanhar sua busca pelo sonho do mestrado. O mais importante, ganhei uma amiga. Amiga que me incentiva o tempo todo. Lucia me deixa doida: "você tem que 
pesquisar, você tem que escrever, você tem que tentar, vai estudar Paloma!!"

Hoje, me sinto Pedagoga e percebo que minha história de aprendiz foi e é marcada pela educação, especialmente, pela escola pública. Nas discussões da minha mãe, nas experiências vividas com ela. Nas lutas com as colegas de turma. Nas pesquisas e aulas com Lucia. Foi esse processo de construção e desconstrução de conceitos, ideias e sentimentos que marcou minha formação. E hoje posso dizer que aprendi que nada acontece por acaso. E que todas as coisas concorrem para o bem daqueles que amam a Deus, daqueles que são chamados segundo o seu propósito.

07 de setembro de 2012. Paloma Oliveira Bezerra

A narrativa de Paloma acima é um fragmento que reflete a sua formação, a sua vida-formação. É uma história verdadeira, carregada de emoção. São aspectos pequenos de um todo. Aspectos de uma geração, mãe professora, filha professora; aspectos de um início, início de uma luta política por melhorias, aspectos de uma identidade em construção. Hoje, Paloma é professora e mestranda em Educação pela Universidade Federal de Uberlândia e os frutos de uma identidade histórica, política e culturalmente construída já afloram na pessoa dela. Lembro-me bem daquele dia, ela começou a ler e logo sua voz falhou. Lágrimas encheram os seus olhos. Ao final da leitura, todos naquela sala tinham lágrimas nos olhos.

A narrativa de Daniela também demarca a sua formação.

De saia plissada azul de tergal, camisa branca com bolinhas vermelhas, tênis conga e meias brancas até quase nos joelhos, marias-chiquinhas, até parece que foi ontem quando minha mãe, no ano de 1982, de mãos dadas, me levou para o primeiro dia de aula no prezinho, não conhecia ninguém, a tia Laís me recepcionou na porta da sala de aula e indicou onde seria o meu lugar de sentar, que frio na barriga! Sensação estranha de não conhecer ninguém.

No dia da minha primeira formatura estávamos padrão, vestidos de camisetas brancas, as meninas de saia e os meninos de calças compridas azul marinho.

A mesma sensação estranha de "não conhecer ninguém", repetiu-se outras vezes. Quando larguei minha turminha, as musiquinhas e o parquinho e passei a estudar, em 1983, no E.E.P.G "Prof. Walter Scheppis" agora entrei na escola grande, não posso mais querer brincar como antes. As aulas da $1^{o}$ série eram muitas chatas, sempre perguntava:

ler?

- Para que devo aprender a fazer bolinha e tracinho, se já sei

Meu pai e o prezinho já haviam me ensinado a ler e escrever!

Tia Alice era muito paciente, baixinha, gordinha, já estava perto da aposentadoria, muitas vezes questionei: 
- Por que não chamá-la de vó Alice? Ela me transmitia muito mais essa imagem.

Depois veio a tia Benedita na $2^{\circ}$ série, ela sempre cantava as musiquinhas da escola, ensaiava a turma para apresentações no pátio, lembro bem da apresentação com a música do "Ursinho Pimpão" da Turma do Balão Mágico.

Era uma prática naquela época de ir um fotógrafo nas escolas para tirar fotos dos alunos para montar um calendário e depois passava de casa em casa vendendo aos pais.

Minha mãe dizia que não tinha dinheiro, mas sempre comprava, não queria que as fotos dos filhos ficassem com estranhos.

$\mathrm{Na} 3^{\circ}$ série a professora Maria da Glória era muito rígida, já ganhei uns chacoalhões para calar a boca:

- Daniela, cale a boca você parece uma matraca!

Todo dia entravamos em fila, a professora passava a ordem:

- Coluna de dois, menores na frente.

Disputava o último lugar para me sentir a maior da sala. Todos os dias havia hasteamento da bandeira do Brasil as $08 \mathrm{~h}$ da manhã e os alunos eram escolhidos para cumprir tal tarefa, e para mim era motivo de orgulho, assim como cantar o hino nacional.

$\mathrm{Na} 4^{\circ}$ série passei por várias professoras, começou com professora Solange, passou para Neuza e por último a titular da sala, professora Severina, que passou vários meses fora por conta de uma licença saúde.

Cheguei na $5^{\circ}$ série, no ginásio, novamente senti aquele friozinho na barriga, um monte de professores, um monte de disciplinas, conversa demais e demorava para copiar, de repente batia o sinal a lousa estava cheia de matéria e outro professor entrava e apagava tudo, que desespero. Na hora do recreio, enquanto algumas colegas ficavam escondidas brincando de "gosta desse?", preferia ficar na quadra brincando de vôlei ou de pega-pega.

"Sete de setembro, data tão festiva, é uma grande festa nesta terra tão querida", os ensaios da marcha, a batida do tambor e o sonho de um dia participar da fanfarra, mas a única coisa que consegui foi marchar no pelotão. E então, mais um ano de greve dos professores, parecia que já fazia parte do calendário escolar, por isso minha mãe resolveu me tirar do colégio público e colocar numa escola particular. Chegando lá, novamente o frio na barriga, novamente irei para um lugar onde não conheço ninguém!

Em 1988, no novo colégio, Domingos de Moraes, não tinha mais hasteamento de bandeira e raramente cantava-se o hino nacional, mas foi lá que consegui fazer parte na comissão de frente e carreguei a bandeira do Brasil. Nessa escola conheci a professora Claúdia Mara, ela adorava, como castigo, colocar um chapéu com orelha de burro nos alunos e mandava sentar desse jeito no corredor, foi com ela que despertei o gosto por Ciências. Juntamente com os desenhos animados que assistia na época, acreditava que poderia mudar o mundo. Na $8^{o}$ série já tinha certeza da minha escolha e fui fazer o vestibulinho para o curso de Técnico em Química.

- E agora? Entrei no E.M.S.G " $1^{\circ}$ de Maio" no turno noturno, não posso mais me comportar como uma moleca, afinal de contas a noite a noite o pessoal é mais adulto. E o vôlei?

Eram muitas perguntas na cabeça de uma adolescente que se achava estranha. No curso técnico as coisas eram bem diferentes, mas não tinha maturidade de levar as coisas mais a sério, de estudar mais, 
não pensava no mercado de trabalho. Só queria aprender Química, ouvir meu Rock'n'Roll, pintar meus cabelos de Pink, usar unhas azuis e batom roxo.

No final do curso técnico a dúvida:

- Que carreira, dentro da Química, deverei seguir? Tudo, menos ser professora!

Optei em fazer o curso de Engenharia Química e por ironia do destino, no segundo ano, uma prima minha que trabalhava na secretaria da escola Walter Scheppis, me perguntou se havia interesse em ministrar as disciplinas de Química e Física para uma turma de $1^{o}$ ano vespertino, pois havia uma vaga para professor. Arrisquei e fui enfrentar a sala de aula, e assim a engenheira começava a abrir espaço para a Daniela professora.

Fim!

Daniela, diferentemente de Paloma, narra seu período de escolarização e como ela foi se fazendo professora. Uma narrativa de uma aluna que se mostrou rebelde no decorrer dos anos, mas que sabia bem o que queria - Química. Na está na história escrita, mas está na história narrada o fato de Daniela ter feito, posteriormente, a graduação em Licenciatura em Química e ser hoje professora da Universidade Estadual do Sudoeste da Bahia, Campus de Itapetinga. Hoje Daniela dá mais lugar a professora, aprende com os pedagogos de maneira muito simples. Isso só foi/é possível porque ela se abriu para isso. A aprendizagem ocorre quando o sujeito se permite aprender, consigo mesmo e com os outros. A educação, nesta perspectiva, é vista como um caminho a se percorrer para aprender. Nele, Daniela tem caminhado.

Ninguém nasce professor, torna-se professora, já diz Fontana (2000) e isso acontece por motivações diferenciadas e de maneira diferente. Foi dessa forma que Daniela professora foi nascendo e vem se modificando.

A história de Aricelma reflete bem essas diferentes formações:

Bem, na minha infância escolar nunca fui rainha do milho, nunca fui escolhida pra representar a sala nos festejos da escola, nunca fui à escolhida dos meninos como namoradinha nem como par pra dançar o São João, também nunca fui a queridinha da professora, talvez porque eu era muito tagarela e não parava quieta e só ouvia: "Tem prego na sua cadeira Aricelma? Tem formiga na sua cadeira Aricelma?" Entretanto, eu me achava uma criança comunicativa, criativa, queria ser artista, mas por incrivel que pareça não tinha a chance de me mostrar na escola. Na época, eu acreditava que era por causa da minha cor e então tomava banho de bucha e me esfregava tanto achando que iria clarear, meu cabelo queria que fosse liso, meus olhos queria que fossem verdes, chegava até pintar meus olhos nas fotos com hidrocor verde, meu corpo ai que raiva, magrela, hoje é moda, mas na época eu é que sei o que eu sofria quando me 
chamavam de Olivia Palito. Minha família, essa sim me dava oportunidade, pra minha família eu podia me mostrar e ser aplaudida.

Ginásio, que difícil, uma aula atrás da outra, vários professores, queria ser líder de classe e não conseguia, a matéria que eu mais odiava matemática, sempre fui esforçada em matemática, $e$ passava mesmo sendo na recuperação. Por isso sempre perguntava a minha mãe: "se eu passar de ano você me dá uma bicicleta?" e ela dizia: "sua mãe não tem condições, mas se você perder, ganha uma surra" e sempre passava de ano, achando eu que era por medo da surra, mas com o tempo compreendi que não e vocês vão compreender também.

Recordo-me de todos os professores e vou citar alguns a $1^{a}$, Sonia, professora de matemática, tinha muito medo dela, e de repente eu adoeço, tive um problema toxoplasmose visual grave, na época, presente de grego pra minha mãe, pois foi no aniversário dela 25 de outubro, daí então vieram várias dificuldades, falta de dinheiro pra pagar passagem pra Salvador, falta de dinheiro pros exames, pros remédios. Mas Deus prepara tudo, nos enviou Dona Silvinha, que nos hospedou em sua casa, talvez por minha tia ser empregada doméstica dela, mesmo assim eles não tinham nenhuma obrigação de me acolher, mas me acolheram e trataram muito bem. Minha mãe chorava por eu estar doente e eu dizia: "besteira mãe, nós estamos em Salvador, na capital e sem pagar nada, ficando em um apartamento na Barra, saindo de carro", mas na verdade eu entendia o que ela sentia, só não queria demonstrar meu medo. Passei um bom tempo sem frequentar a escola por conta dos meus exames, mas as notícias chegavam, "levantamos uma campanha pra você na igreja católica", "levantamos uma campanha pra você na igreja evangélica". Puxa como as pessoas se importam comigo, eu pensava. Então de volta a minha cidade, retomei os estudos e essa dita professora de matemática, que eu morria de medo me disse: "Aricelma você está em recuperação, pois você não tem nota na terceira unidade, argumentei, mas sem êxito, tudo bem, conversei com minha mãe e ela disse:

"Celma, caso você venha perder de ano não tem problema", eu podia me conformar e não estudar mais, afinal de contas não ia ganhar uma surra mesmo, foi quando procurei um anjo chamado Eliane da Silva Soares que é minha colega hoje em Pedagogia e melhor em matemática daquela época e ela disse: "eu te ajudo sim, e eu ia todos os dias pra casa dela estudar e ela pacientemente me ensinava e sei que tirei dez na prova de recuperação, pois eu anotei as questões e Eliane respondeu dizendo o resultado é esse e era o que eu tinha colocado na prova. Então obrigada Eli, com essa historia de aprendiz pude demonstrar a sua grande passagem em minha vida.

Bem, o problema na visão continuava e no ano seguinte precisei me ausentar novamente, por ironia do destino ou não, o médico que me atendeu passou um medicamento que cicatrizou minha retina no lugar errado, e, além disso, eu poderia perder a outra visão, e olhe aí a tal da matemática de novo me azucrinando. Pronto, lá vou eu pra recuperação de novo por conta da minha ausência, no entanto era outro professor chamado Barreto. E minha família fez um bingo beneficente mobilizando toda minha escola Centro Educacional Alfredo Dutra e em especial esse professor que fez a seguinte proposta em sala de aula: "a cada duas cartelas vendidas o aluno 
terá meio ponto" e vi alunos pegando 10, 20 cartelas, pra me ajudar ou não, isso pouco me importou naquela hora e ele me disse: "essas cartelas servem pra que você também Aricelma" e eu vendi tanta cartela que fiquei com boa nota na unidade, conseguimos pagar os exames e pra completar escapei da recuperação. Esse professor, nunca mais o vi.

Fiz magistério, fiz contabilidade e não optei por nenhum, trilhei outro caminho. E em 2011 precisando de um portador pra entregar um documento urgentíssimo em Salvador, quem eu vejo na rodoviária indo pra Salvador? A professora matemática, mas não tive coragem de pedir o favor, e por incrível que pareça, ela me reconheceu e se aproximou super-receptiva e então tive audácia e ela disse: "claro que entrego, pegue meu telefone e se precisar de algo mais me ligue". Ai que surpresa maravilhosa e a vi com outros olhos naquele momento.

Agora vejam, sabe aquela menina que quando criança queria se mostrar como artista? Ela é back vocal da Banda de Edigar Mão Branca; sabe aquela menina que queria ser líder de classe e não conseguia? Ela é hoje presidente do Partido Verde em Itapetinga; sabe aquela menina que se achava comunicativa e não tinha oportunidade? Ela experimentou ser locutora de rádio e se saiu muito bem; sabe aquela menina que acreditava que sua cor impedia de fazer as coisas, queria ter cabelos lisos, olhos verdes? Ela valoriza sua cor, assume seus cachos e de vez em quando tira onda com lente de contato verde; sabe aquela menina que não era escolhida pra representar a escola nas atividades? Pois é, ela foi chamada pra ser a oradora da turma dos formandos em Pedagogia ano 2012 e todos já estão convidados pra fazer parte de mais uma etapa na vida dela. E pra completar ela é mãe de uma criança maravilhosa chamada João Gabriel que é fonte inspiradora e motivadora para que ela não pare por aí.

Aricelma da Silva Santos

A narrativa dela é emocionante e emocionou a muitos. Aricelma começou cantando a música de "sangrando" de Gonzaguinha. Só depois iniciou a leitura. Diferentes memórias marcam narrativa de Aricelma. São aspetos da formação, da família, da raça, da posição política, da etnia, da mãe. Diferentes pessoas numa só. Nóvoa (1992) já nos falou sobre isso, que somos um e múltiplos, pois não separamos a pessoa do profissional. Somos ao mesmo tempo a mãe, sem deixar de ser a filha; somos irmã, esposa, professora, cantora, tudo ao mesmo tempo. Quando a professora vai dar aula, ela não entra na sala e deixa do lado de fora a mãe, a filha e a esposa que é, por exemplo. Aricelma mostrou nessa história sua multiplicidade.

Ricardina destaca a história de aprendiz a narrar, a história do seu nome. 
Mesmo antes de nascer meu nome já era motivo de polêmica. Minha mãe dizia que se fosse homem se chamaria Pedro em homenagem ao pai dela e meu pai por sua vez dizia que se fosse mulher seria Ricardina em homenagem a sua mãe.

$O$ acordo estava feito, mas quando nasci à estória mudou muito... Minha mãe começou a dizer que uma menina tão pequena não poderia ter um nome tão grande e tão antigo. Então começou o problema, pois ela já queria quebrar o acordo e colocar o nome naquele lindo bebê Cleide. E o tempo foi se passando, todos me conhecendo como Cleide e nada de decidirem sobre o nome oficial, pois meu pai não concordava com minha mãe.

Quando completei um ano, todos me chamavam de Cleide e então meu pai resolveu me registrar e para surpresa de todos, ele chegou em casa com a certidão de nascimento e pam, pam, pam... Ricardina da Silva Pessoa.

Minha mãe ficou tão chateada que não deixava ninguém me chamar de Ricardina e o nome Cleide foi ficando cada vez mais familiar ao passo que o de Ricardina se tornava pavoroso e motivo de muita tristeza, tanto que até na escola os professores só me chamavam de Cleide, mas com oito anos de idade minha família se mudou para Vitória da Conquista e ali minha realidade também começava a mudar.

De repente sentia o mundo caindo aos meus pés, pois ninguém conhecia Cleide, todos ali estavam conhecendo uma garota comunicativa, alegre, estudiosa, porém carregava um 'peso enorme' não aceitava de forma alguma aquele nome. Pedia para que todos me chamassem de Cleide, mas não me ouviam. Eu ficava muito triste, pois naquela cidade, naquela escola as pessoas eram tão cruéis com uma criança, não atendiam um pedido tão simples.

O tempo foi se passando e aos poucos aquele nome foi se tornando familiar, sem perceber já estava me acostumando e entendendo que o que torna diferentes nos nomes é a personalidade das pessoas, como damos vida a esses nomes. E para ironia do destino quase todo mundo me chama de Ricardina e meu pai só me chama de Cleide.

12 de novembro de 2012 Ricardina Pessoa Tarquinio

A história de Ricardina se diferencia das outras pelo recorte que tem - do nome. O nome marca uma vida, como marcou a dela. O nome é representação da identidade, por isso tem a ver com a personalidade, tem a ver com quem somos (CIAMPA, 1995). A constituição do nome de Ricardina começa antes do seu nascimento, por traz de um nome vai se formando um sujeito, com "formas, cores, odores", ou seja, com um modo de ser, com o seu modo de ser, ser Cleide na infância em Itapetinga, e ser Ricardina, na certidão de nascimento, que passou a ser Ricardina ainda na infância em outra cidade, Vitória da Conquista. Assim, os sujeitos vão se constituindo com o tempo, se mostrando que é. O mais importante de tudo é como o sujeito que narra se constitui. E Ricardina da Silva Pessoa, eu já tinha sido Cleide, tornou-se Ricardina Pessoa Tarquinio, após o 
casamento. E teve que incorporar a sua personalidade outros aspectos de sua identidade - a de esposa. As mudanças faz parte da formação, essas memórias mudam a formação do sujeito.

Mariana fala da escolarização, das escolhas, da família e das mudanças:

História de Aprendiz

Meu nome é Mariana Moura, nascida e criada em um município de Ilhéus (Banco Central). Sobre minha vida como estudante, têm coisas que quero esquecer e outras que quero levar comigo pra sempre. Eu estudei em uma escola municipal de Banco Central desde meus 4 anos até os 12 anos de idade. Nos primeiros anos na escola tive professoras que me tratavam como filha e tinham muita paciência comigo, mas também encontrei nessa trajetória professoras que eu me perguntava o que estavam fazendo no Ensino Fundamental I, trabalhando com crianças que precisam de atenção $e$ carinho. Uma delas me beliscava tanto que me deixava roxa e pra completar minha mãe trabalhava na escola e apoiava a atitude dela porque ela achava que eu estava aprontando mesmo. Isso de minha mãe trabalhar lá me deixou tão presa e me obrigou a ser uma aluna exemplar que quando entrei no ensino médio me rebelei que até brigar com professores eu briguei. Nunca fui uma aluna ruim e nem tirava notas vermelhas e nem sei o que é recuperação, eu tinha medo do meu pai e por isso eu me exigia muito e queria a perfeição na escola. Quando eu entrei no ensino médio foi um momento difícil porque eu tive que sair de casa e ir morar com minha tia em Ilhéus e deixar a minha mãe ali na porta chorando, pra mim foi triste. Acabei indo por que meu pai me convenceu que era o melhor e que lá eu seria uma pessoa diferente. Realmente meu pai tinha razão, eu mudei e virei uma menina rebelde e popular no colégio (influência das amizades). Mas nunca parei de estudar e de me dedicar pra prestar o vestibular. E lá estava eu me "formando" e me preparando para prestar vestibular e mudar radicalmente meu viver. Fiz cursinho, vivia na biblioteca. Mas o destino me reservava uma surpresa. Prestei vestibular pra Biologia na UESC e Pedagogia na UESB e orava a Deus pra que eu passasse na UESC porque em Itapetinga eu não queria morar de jeito nenhum e por cuspir tanto em Itapetinga o destino me fez perder na UESC e passar aqui. Eu digo que não foi e não é fácil estar morando aqui, as saudades de minha mãe, de meu pai e de minha família em geral e dos amigos, me destrói. Mas Deus me ajuda e eu estou aqui dando o meu sangue pra concluir meu curso de forma satisfatória e me formando como um ser humano de verdade.

A história de Mariana remete a escolarização, a tempos de privação na escola, a rebeldia, a escolhas. Uma história que começa em Banco Central, distrito do município de Ilhéus, na Bahia. Uma história de mudanças geográficas e mudanças interiores, na personalidade. As subjetividades estão presentes, pois é uma história de saudades que remete a uma luta, essa, de tornar-se pedagoga. 
Dessa forma, as verdades presentes nas histórias aprendiz aqui contadas nos faz refletir sobre as mudanças provocas por elas. Dominicé (2010) diz que quando há formação há mudança. Elas aparecem na escrita, na fala, na personalidade; elas são aspectos da formação.

Há pessoas que fazem parte de nossas histórias, Dominicé (2010) fala que todas das pessoas citadas numa narrativa são importantes e exerceram influência no percurso da vida-formação. Nas narrativas acimas muitas pessoas são citadas, essas fazem parte do processo constitutivo dos sujeitos que narraram.

Assim, a formação docente dá-se também a partir das narrativas, possíveis nessas histórias, através das memórias. As narrativas possibilitam, na formação de professores, desvelarem o processo de formação ocorrido no decurso da vida. A narrativa da trajetória de vida e da trajetória profissional revelam histórias, espaços e tempos contidos na memória, e ainda a fertilidade da abordagem, a subjetividade, as representações e práticas de diferentes aspectos vividos no cotidiano. Nelas estão as marcas das experiências escolares, familiares e da formação. De acordo com Souza (2006), a narrativa abrange, nesse trabalho, a dimensão da aprendizagem, buscando dar ênfase a formação pela reflexão sobre as experiências vivenciadas no processo de aprendizagem ao longo da vida. Como “[...] a formação é, inevitavelmente, autoformaçao. Uma articulação criadora de sentido a partir da dimensão histórica de cada um" (PASSEGGI et al., 2006, p.266), essa autoformação é um processo que possibilita ressignificar a identidade pessoal e profissional.

\section{Considerações finais}

As trajetórias reconstruídas nos permitiram entender aspectos da formação e da vida desses sujeitos. Assim, consideramos que muitas outras histórias de inserem nas histórias delas professoras o que permitiu vários enfoques no âmbito das história de aprendiz. Através dessas narrativas percebemos uma história, uma história individual e social, singular e plural. "Ouvimos" história e histórias que atravessam épocas e nos permitem entender escolhas. É importante pensar que a escolha de que falamos marca o cotidiano, a dimensão do tempo, a vida e os nossos conhecimentos; marca a nossa formação. 


\section{STORIES OF APPRENTICE: \\ MEMORIES NARRATIVES AND TRAINING INSTRUCTOR}

ABSTRACT: This study aims to report stories apprentice produced under the extension course "Training of teachers: a challenge of contemporary" developed at the State University of Southwest Bahia, Campus Itapetinga and formative aspects present in the stories. The discussion focused on the ongoing teacher training in contemporary and meetings were held weekly. Thus, this study aimed to identify the stories narrated apprentice, memories and these formative experiences in her present. For some were just stories to other memories here show that it is more than that, is training. From the analysis of the narratives was possible to see how individuals have changed, formed, lived. Thus, consider the stories of learner narratives fragments of life, allowing reflection, which enables self-training.

KEY WORDS: Written himself. Learning. Self-education.

\section{REFERÊNCIAS}

BRANDÃO, V. M. A. T. Labirintos da memória: quem sou? São Paulo: Paulus, 2008.

CIAMPA, A. A estória do Severino e a história da Severina: um ensaio de psicologia social. São Paulo: Brasiliense, 1995.

DOMINICÉ, P. O processo de formação e alguns dos seus componentes relacionais. In: NÓVOA, A.; FINGER, M. O método (auto)biográfico e a formação. Natal: EDUFRN; São Paulo: Paulus, 2010. p.81-95.

FONTANA, R. A. C. Como nos tornamos professoras? Belo Horizonte: Autêntica, 2000.

NÓVOA. A. Os professores e as histórias de sua vida. In: NÓVOA, A (Org.). Vida de professores. Lisboa: Porto, 1992. p.11-30.

NUNES, C. Formação docente no Brasil: entre avanços legais e recuos pragmáticos. Teias, Rio de Janeiro, n.1, p.16-30, jan./jun. 2000.

PASSEGGI, M. C. et al. Formação e pesquisa autobiográfica. In: SOUZA, E. C. (Org). Autobiografias, história de vida e formação: pesquisa e ensino. Porto Alegre: EDIPUCRS, 2006. p.257-268.

PERRENOUD, P. et. al. As competências para ensinar no século XXI: a formação dos professores e o desfio da avaliação. Porto Alegre: ARTMED, 2002.

SOUZA, E. C. O conhecimento de si: estágio e narrativas de formação de professores. Rio de Janeiro: DP\&A; Salvador: UNEB, 2006.

TARDIF, M. Saberes docentes e formação profissional. Petrópolis: Vozes, 2002. 